\title{
Imigrantes indesejáveis. A ideologia do etiquetamento durante a Era Vargas
}

\author{
Maria Luiza Tucci Carneiro
}

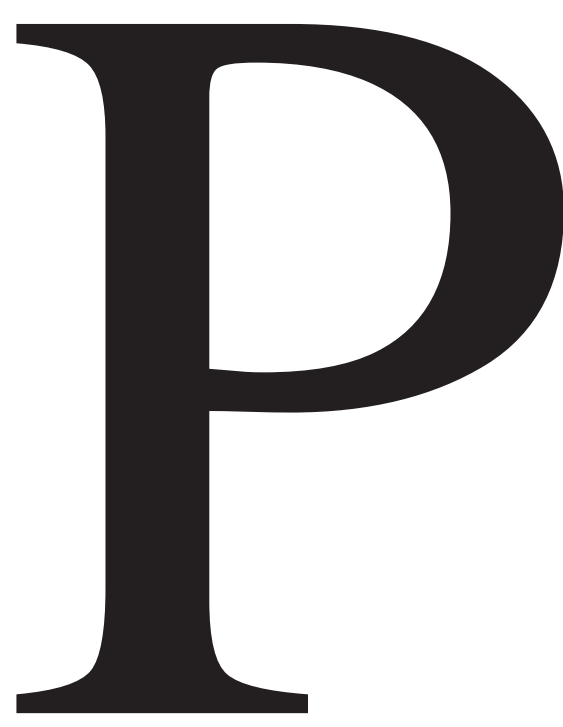

\section{A REPRESENTAÇÃO DO “OUTRO"}

esquisando nos arquivos brasileiros tive a oportunidade de identificar distintas formas de representação da imagem do imigrante, que, em diferentes momentos, tornou-se objeto dos discursos diplomático e policial, da literatura, da caricatura, da fotografia e das artes plásticas, em especial. Políticos, intelectuais, artistas, médicos, psiquiatras, diplomatas e autoridades policiais encontraram neste personagem alguns sinais de estranhamento e repulsa. O inventário apu-

MARIA LUIZA TUCCI CARNEIRO é historiadora, coordenadora do Laboratório de Estudos sobre Etnicidade, Racismo e Discriminação (LEER) do Departamento de História da FFLCH/USP e autora de, entre outros, Dez mitos sobre os judeus (Ateliê). 
rado dessa documentação demonstra que a convivência com o imigrante por parte de alguns segmentos da população brasileira se fez, sempre, limitada por um discurso intolerante modelado por teorias eugenistas e políticas excludentes, principalmente durante o governo de Getúlio Vargas (1930-1945) e de Eurico Gaspar Dutra (1946-1954).

A construção da identidade nacional foi, muitas vezes, modelada por valores peculiares do pensamento racista moderno que não prescindiu das teorias importadas da Europa. A eugenia conquistou espaço entre as elites que debatiam e pensavam sobre a questão imigratória interpretada como "problema", ou seja: como uma ameaça. Desde a década de 1920, o estrangeiro passou a ser classificado nas categorias "desejável” ou "indesejável”, selecionado segundo critérios políticos, étnicos, culturais e religiosos. Autoridades do alto escalão do governo argumentavam que, caso o imigrante não fosse selecionado entre os melhores exemplares, poderia "desfigurar" e "desnaturalizar" a população brasileira, principalmente se fosse judeu. Segundo afirmou Ernani Reis, secretário de Francisco Campos, ministro da Justiça e dos Negócios Interiores, em seu artigo "Imigração e sentimento nacional", publicado em 1943 no jornal carioca $A$ Noite:

"[...] a introdução maciça de populações com o fim de encher os espaços vazios do nosso território, isto é, a introdução de uma quantidade tal de imigrantes que superasse a nossa capacidade atual de assimilação, significaria fatalmente a desfiguração e o desnaturamento, do ponto de vista nacional, de vastas extensões do solo pátrio. Da tentativa de acrescer demograficamente o país resultaria, destarte, uma diminuição espiri- tual da pátria e essa diminuição espiritual poderia tornar-se, mais tarde, um fator da própria redução material da pátria, a saber, uma ameaça à sua unidade" ${ }^{1}$ (Reis, 1943).

Como objeto de análise optamos por observar o processo de construção das figuras do judeu e do japonês, que, desde as últimas décadas do século XIX, foram estigmatizados e tratados como "indesejáveis" e/ou como "raça inferior". Daí as expressões: perigo semita e perigo amarelo, além de outros perigos como o perigo vermelho/comunista. Nos propomos a recuperar as matrizes desse pensamento intolerante que, certamente, colaborou para a persistência de políticas discriminatórias por parte do Estado brasileiro instigando manifestações de violência, física e/ou simbólica. Importante avaliarmos o potencial dessas imagens enquanto fontes históricas e meio de conhecimento para a reconstituição dos estigmas e estereótipos que povoam o imaginário coletivo.

Essa releitura nos convida a lançar um olhar crítico sobre os múltiplos discursos que nos instigam a analisar o passado a partir de indagações motivadas pelo presente. $\mathrm{O}$ racismo persiste no contemporâneo valendo-se das novas mídias que continuam a manipular o imaginário coletivo, ainda que com novas roupagens. É fato que, na primeira metade do século XX, existia uma tensão entre a força das construções imaginárias e a tentativa institucional de interferir na produção de significações. No seu con-

1 Ernani Reis atuou como braço direito de Francisco Campos, ministro da Justiça e Negócios Interiores, tendo participado diretamente da elaboração e aplicação das políticas imigratórias seletivas e excludentes que vigoraram durante o Estado Novo (Koifman, 2012). 
junto, a iconografia nos oferece expressivos elementos para o estudo das mentalidades e da persistência dos mitos no imaginário brasileiro. Vinculando a história da imigração à arte política no Brasil, temos a possibilidade de reconstituir um amplo quadro das estruturas mentais de uma época. No entanto, apesar dos avanços da historiografia brasileira nestas últimas décadas, muitas dessas imagens têm servido como meras “ilustrações” para os estudos imigratórios, não merecendo o devido tratamento crítico enquanto fontes históricas portadoras de múltiplos significados e significações. $\mathrm{Na}$ realidade, as imagens trazem - subjacentes à informação iconográfica propriamente dita - um manancial de outras informações que exigem do pesquisador uma reflexão atenta às metáforas e analogias empregadas pelo autor da imagem. Lembramos que é através das deformações, das omissões e das "entrelinhas" visuais e textuais que encontramos um campo fértil para os estudos sobre intolerância avaliada sob o viés da história das mentalidades, como tem enfatizado Boris Kossoy em seus estudos sobre o efêmero e o perpétuo na imagem fotográfica (Kossoy, 2014).

O imigrante, interpretado como o "outro", tornou-se foco de avaliações apressadas que, muitas vezes, culminaram em atitudes de repulsa e ódio. Há evidências da aplicação de ideias oriundas do pensamento eugenista que, certamente, inspirou práticas discriminatórias. Imagens de todos os tipos serviram para registrar diferentes percepções, nem sempre destituídas de preconceitos herdados da civilização europeia. Essas imagens, por sua vez, não devem ser dissociadas dos valores e da autoimagem de seus produtores, que, influenciados pela persistência de uma mentalidade intolerante, promoveram a produção de imagens estereotipadas dos chineses, japoneses, portugueses, ciganos, negros e judeus, em particular. Enquanto alguns segmentos dos brancos europeus se faziam distintos por seus "ares de civilidade", outros eram apontados como elementos perigosos para a composição da população brasileira. Portanto, as fontes iconográficas devem ser "submetidas à criteriosa análise das suas condições de produção e/ou de recepção", podendo funcionar, como muito bem escreveu Voigt (2013, pp. 91-105), "como chaves heurísticas da realidade de uma época passada".

Muitas das imagens estereotipadas reproduziam e reforçavam o discurso oficial das autoridades brasileiras que insistiam na imagem do "trabalhador ideal", que, em momentos distintos, replicava valores preconceituosos. Portanto, cada imagem em particular se apresenta como "carregada de sentidos", ou seja: o governo brasileiro estava interessado em preencher os espaços vazios do território nacional desde que as correntes imigratórias garantissem o branqueamento da população. A solução estava em impedir a entrada de negros, judeus e japoneses, principalmente, de forma a não aprofundar o abismo provocado pela "má-formação étnica" herdada do passado escravocrata e do liberalismo republicano. Assim, a adoção de políticas imigratórias restritivas se fez fundamentada na ideologia do trabalho e da segurança nacional, pensamento que persistiu durante todo o primeiro governo de Getúlio Vargas (1930-1945) e de Eurico Gaspar Dutra (1946-1954) (Carneiro, 2001, pp. 64-96; Movschowitz, 2001; Carneiro \& Takeuchi, 2010; Silva, 2010). 


\section{A TEORIA DO ETIQUETAMENTO}

Entre 1930 e 1945, o governo de Getúlio Vargas colocou em prática uma política imigratória restritiva e racista. Vetou, com base em argumentos racistas, a concessão de vistos aos judeus, ciganos, negros e japoneses. $\mathrm{O}$ discurso racista reunia atributos que, no seu conjunto, transformavam essas minorias em seres indesejáveis, "indigestos". Em particular, não interessava ao Brasil receber os judeus que fugiam do nazifascismo porque - segundo as autoridades brasileiras - eles colocavam em risco o processo de construção da raça e da brasilidade. Essa posição, radical em sua essência, vinha atrelada a uma prática orientada para o futuro da nação, que deveria incentivar apenas a entrada de "bons" imigrantes, tendo como critérios elementos étnicos e ideológicos. Assim, as correntes imigratórias não poderiam estar comprometidas com a ideia de corrosão social e com as doutrinas exóticas, traços pertinentes à imagem estereotipada dos judeus, avaliados como inassimiláveis, comunistas, parasitas e avessos ao trabalho agrícola. Segundo esse raciocínio, a ideologia do trabalho prestava-se como critério seletivo, acobertando uma mentalidade racista que pontuou, por várias décadas, o discurso oficial brasileiro.

O controle desse fluxo imigratório se fazia em nome da ordem, sendo aplicado em primeira instância no exterior e, posteriormente, no território nacional. Os diplomatas brasileiros em missão no exterior cuidavam de fazer uma primeira seleção com o objetivo de impedir a saída da Europa dos "indesejáveis", em sua maioria “apátridas". A estratégia adotada pelo Ministério das Relações Exteriores do Brasil, o Itamaraty, foi de aplicar um conjunto de normas de controle que, por não serem condizentes com a Constituição brasileira, foram impostas por meio de circulares secretas que vigoraram desde 1937 até 1953, trazendo graves consequências para os refugiados políticos, judeus e não judeus, que nem sempre conseguiam um refúgio seguro que garantisse a sua sobrevivência.

Calculo que, no mínimo, cerca de 14 mil judeus refugiados ingressaram no Brasil portando falsos documentos e com vistos de católicos, como turistas ou em trânsito. Mesmo assim, apesar das restrições, alguns receberam vistos permanentes por terem subornado a autoridade diplomática, por terem adquirido terras no Brasil através de projetos de colonização ou por portarem vistos aprovados dentro das cotas permitidas pela legislação brasileira. $\mathrm{O}$ controle sobre a comunidade dos refugiados radicados no Brasil cabia ao Ministério da Justiça e dos Negócios Interiores, que, através da polícia política, saía em busca dos "ilegais". Movida por lógica própria - a da desconfiança - e com a função específica de purificar a sociedade das raças e ideologias ditas "malditas", "degeneradas" ou "perniciosas" à ordem social, a polícia política brasileira (Departamento de Ordem Política e Social - Dops) aprimorou-se em identificar os indesejáveis com base no status de evidência. Ao longo de sua existência, o Departamento Estadual de Ordem Política e Social de São Paulo (Deops/SP - 1924 a 1983) efetuou investigações sistemáticas com o objetivo de reconstituir o passado de grupos políticos ou de cada cidadão em particular. Fragmentos de vidas comuns encontram-se registrados nos prontuários policiais que hoje comprovam a violação dos direitos humanos e a humilhação sofrida por todos aqueles que, 
um dia, foram intimados, fichados, presos ou expulsos como indesejáveis por romperem a normalidade majoritária. As atitudes repressivas da polícia e as consequências nefastas de uma prisão acabaram por gerar diretrizes de comportamento impondo aos cidadãos o autocontrole e a autocensura (Holloway, 1997, pp. 27-30). No caso de reações em contrário, acionava-se um discurso estereotipado e carregado de estigmas que, propagado pelos meios de comunicação, contribuía para fortalecer o arsenal negativo edificado contra alguns grupos tradicionalmente excluídos. Foi nesse contexto que a polícia política assumiu importante papel junto à dinâmica instituída pelo processo de domesticação das massas.

Pesquisando a documentação produzida pelos diplomatas brasileiros no exterior, assim como os prontuários nominais e dossiês organizados pela polícia política brasileira, constatei diferentes discursos que, apesar de naturezas distintas, coexistiam expressando uma verdade aparente. Esses documentos - liberados para consulta pública e aos pesquisadores somente a partir de 1995 - passaram por um processo de gerenciamento cuja desmontagem é imprescindível para a reconstituição da ideologia do etiquetamento fundamentada na lógica da desconfiança. Tanto as autoridades diplomáticas quanto as policiais tinham como objetivo "purificar" a sociedade das ideias insanas e das "raças indesejáveis"². Para classificar o sus-

2 A polícia política, desde a sua criação em 1924, recebeu diferentes denominações. Para distinguir a sua ação em nível federal e estadual estaremos usando, ao longo deste trabalho, a sigla Dops, para o órgão federal, e Deops, para o departamento ou delegacia em nível estadual, seguido da sigla do estado correspondente. peito e comprovar a perniciosidade das suas ações procurava-se também por indícios de sua "raça” e/ou vestígios do seu passado interpretados segundo cânones científicos. Lembro que as teorias de Cesare Lombroso (1835-1909) tornaram-se referências nas aulas de antropologia criminal das faculdades de direito no Brasil.

Cruzando as versões diplomáticas com as policiais e aquelas veiculadas pela grande imprensa temos possibilidade de recuperar elementos que direcionavam o raciocínio "lógico" dos ordenadores. Geralmente o imigrante ou refugiado judeu era descrito como desumano, imoral e violento, imagem que se fazia reforçada pela fotografia e pela charge que lhes davam forma. As possibilidades de identificação eram múltiplas, ganhando estatuto de prova documental. $\mathrm{O}$ olhar viciado do investigador policial sabia, de antemão, o que deveria procurar: passaportes com vistos falsos e/ou vencidos, livros de reza, jornais, panfletos, livros, partituras musicais, cartões-postais, boletins, circulares, manifestos e filipetas, em qualquer idioma e grafia. Dos álbuns de família "arrancavam-se" fotografias que, inseridas nas folhas dos prontuários e dossiês, se prestavam para ilustrar a versão pretendida pela autoridade investida do poder de decisão.

Identificando o perfil dos judeus refugiados do nazismo através das Fichas Consulares de Qualificação conseguiremos perceber algumas dessas formas de controle e os múltiplos subterfúgios acionados por aqueles que procuraram sobreviver à violência nazifascista. Tanto os documentos diplomáticos como os documentos policiais nos ajudam a definir certas identidades individuais e de grupo, demonstrando a formação de redes de solidariedade entre imigrantes e nacionais. 
Muitas vezes, constatamos a coexistência de dois mundos paralelos: o submerso, visível, dito "real"; e o clandestino, movediço, sombreado, dito recluso. Sobre os ilegais recaía a culpa pela infração: eles haviam ultrapassado os limites do permitido. Se reincidentes transformavam-se em "reféns do seu próprio passado", distinção formal decorrente do estigma da criminalização, do labelling approach ${ }^{3}$ ou teoria do etiquetamento.

A sistemática negação de vistos aos judeus ainda no exterior e, posteriormente, a vigilância policial no Brasil devem ser avaliadas como a formulação de uma resposta institucional à ameaça representada por aqueles que atentavam contra a estabilidade social, política e religiosa. Tanto os relatórios políticos mensais produzidos pelos diplomatas no exterior como os relatórios policiais e os autos de busca e apreensão demonstram que, na maioria das vezes, o julgamento das autoridades policiais se fazia baseado em suposições. Essa linguagem tomou conta do discurso ordenador que colocava em prática a teoria do etiquetamento,

3 Teoria do etiquetamento social ou labelling approach surgiu na década de 60 nos Estados Unidos. Dentre os principais teóricos cabe citar Garfinkel, Goffman, Erikson, Cicourel, Becker, Schur e Sack. Em resumo, trata da criminalidade não só como uma qualidade de uma determinada conduta, mas como o resultado de um determinado processo de estigmatização da conduta e daquele que a praticou. Segundo Alessandro Barata (2002), o etiquetamento consiste na sustentação de um processo de interpretação, definição e tratamento, em que alguns indivíduos pertencentes a determinada classe interpretam uma conduta como desviante, definem as pessoas praticantes dessa mesma conduta como desviantes e empregam um tratamento que entendem apropriado em face dessas pessoas, que as dessocializa, embrutece e estigmatiza. Cf. artigo disponível em: http:// radardacidade.com.br/2013/08/labelling-approach-a-teoria-do-etiquetamento-social. também conhecida como labelling aprouch, conceito analisado por Howard S. Becker em seu livro Outsiders: estudos de sociologia do desvio. Essa teoria é enquadrada como a "desviação", ou seja, uma qualidade atribuída por processos de interação altamente seletivos e discriminatórios. O "indesejado" ou o "outro" é demonizado e animalizado exigindo, por parte das autoridades, intervenções preventivas que, por sua vez, aumentam o poder punitivo do Estado aproveitando-se dos medos populares.

O judeu foi visto, nas décadas de 30 e 40, como pessoa desajustada, vulnerável e propensa ao desvio, sendo avaliada como fonte de perigos e incertezas. No seu país de origem ele era classificado e tratado como uma sub-raça e no Brasil era perseguido como um refugiado ilegal e pernicioso. A veiculação de notícias na imprensa e a circulação de obras antissemitas contribuíram para aumentar ainda mais a reprovação social, estigmatizando-os como estranhos à ordem nacional. Esse processo de estigmatização deixou vestígios no imaginário coletivo, que continua a se alimentar de um conjunto de mitos políticos (Brissoli, 1998; Becker, 2008; Garland, 2008).

\section{0 "OUTRO" NO MUNDO DAS REPRESENTAÇÕES}

Nossa proposta metodológica insere-se no campo da história cultural onde arte e política se prestam para identificar e comparar as visões de mundo diante de um mesmo tema, neste caso, o imigrante indesejável, tratado como o "outro". Procuramos reunir um conjunto de fontes que possibilitem reconstituir o processo de construção da 
imagem do imigrante enquanto modelo de representação. Estaremos atentos às interferências dos discursos "anti-imigrantes", que no seu conjunto apresentavam ambivalências e ambiguidades notáveis, conforme notou Federico Croci, no caso dos japoneses. Oscilavam "entre o estereótipo de trabalhador honesto, dócil, pacato, diligente e o agente do perigo a serviço de um país imperialista, portanto um potencial perigo político e racial" (Croci, 2010, p. 284). A imagem do judeu que persiste, por sua vez, é de um parasita que vive do trabalho alheio, revolucionário bolchevique e/ou explorador capitalista, e/ou articulador de um complô para dominar o mundo.

Considerando que parte significativa dos fluxos imigratórios para o Brasil se deu também na esteira das diásporas políticas ao longo da primeira metade do século XX, sobretudo no pós-Primeira Guerra Mundial, nossa análise se faz também direcionada para a imagem do refugiado judeu apresentado como perigo étnico-político induzida pela persistência de mitos políticos. Somam-se novos atributos: do cidadão sem pátria, representante de uma raça degenerada. É quando a mentira se transforma em verdade, evidência comum aos regimes ditatoriais ou totalitários. O discurso era construído de forma a culpabilizar o "outro", que, por alguma razão, não deveria compartilhar da felicidade idealizada por aqueles que impunham a ordem nacional. Em consequência: decretava-se a repressão aos elementos nocivos à sociedade firmando, em várias instâncias, o pacto entre o Estado ordenador e a população brasileira cooptada pela propaganda política e pelo medo ao desconhecido. Os judeus eram acusados de promoverem a guerra, os negros, de contribuirem para o atraso do Brasil e os japoneses, de serem "inassimiláveis como enxofre", por viverem enquistados dificultando a assimilação.

Na maioria das vezes, os diferentes "tons" e "perfis de identidade" atribuídos aos imigrantes "indesejáveis" eram inspirados no ideal de superioridade propagado pelas teorias racistas assimiladas dos europeus. Clichês xenófobos e racistas eram reforçados pelas imagens criadas pelos caricaturistas que, através do humor e da sátira política, veiculavam valores preconceituosos nos jornais e nas revistas ilustradas brasileiras (Saliba, 2002). São esses componentes híbridos que pretendemos analisar demonstrando, no caso das charges políticas, que o humor não era tão inocente. As figuras dos imigrantes publicadas nas revistas ilustradas e na grande imprensa expressam os conflitos étnicos, apesar do discurso oficial alimentar o mito da democracia racial e do homem cordial brasileiro.

\section{A BIOTIPIA DO IMIGRANTE IDEAL}

A experiência histórica deixada pelos imigrantes radicados no Brasil é digna de capítulos especiais na história da República brasileira. Em primeiro lugar porque, após a Abolição da escravatura em 1888, os negros, os orientais (japoneses e chineses) e os judeus sempre estiveram presentes no imaginário dos ocidentais; e em segundo por terem suas imagens construídas sob o prisma de estereótipos seculares. No final do século XIX e início do XX, por exemplo, o estado de São Paulo chegou a incentivar a vinda de trabalhadores estrangeiros para as fazendas de café, cujos contratos eram, em grande parte, subvencionados pelo go- 


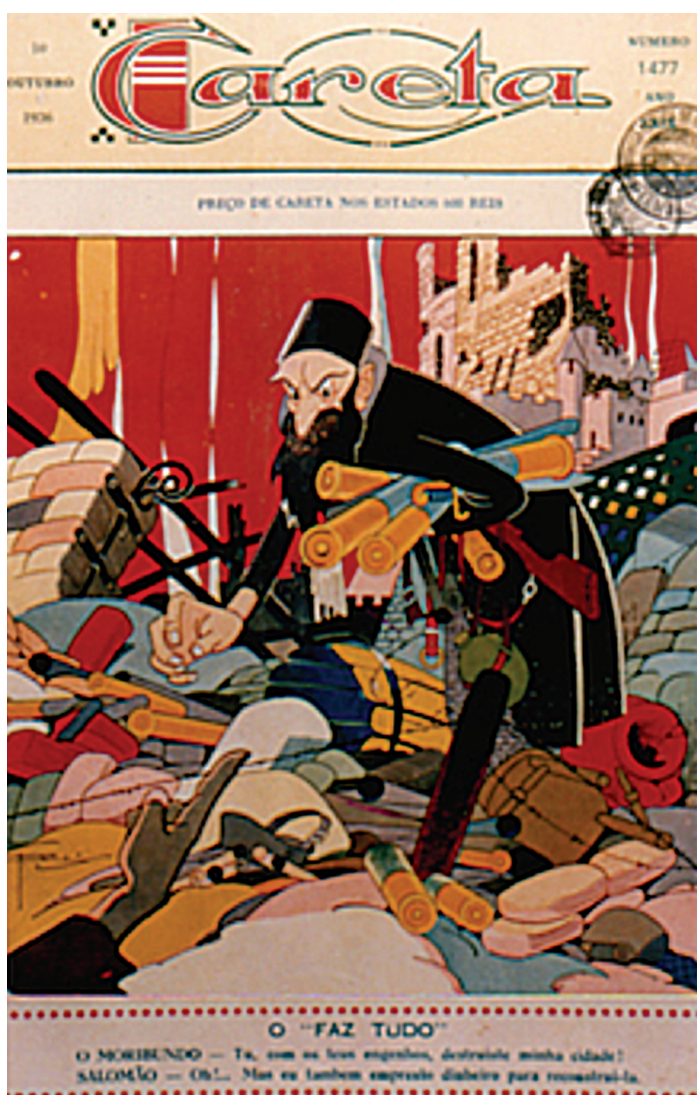

A imagem do judeu "faz tudo".

Charge publicada na revista Careta

(n. 1477), outubro de 1936. Acervo Tucci/SP

verno. O discurso oficial e científico acerca do imigrante ideal se fez, principalmente durante esse período, fundamentado na ideia de assimilação e fusibilidade. Desde o início desse processo de incentivo à imigração ficou evidente que não interessava ao Estado republicano manter em território nacional aquelas comunidades que optassem por preservar a sua identidade étnica e política. Essa situação explica o fato de, em distintos momentos da história republicana, a resistência à assimilação ter gerado situações de conflito. Interessava sim às elites agrárias e políticas a conformidade e a subserviência. No caso da imigração japonesa se faz oportuno o inventário dos manus- critos e impressos antinipônicos produzidos desde o final do século XIX até os anos de 1950, pesquisa desenvolvida por Marcia Yumi Takeuchi (2016) em seu estudo Entre gueixas e samurais: a imigração japonesa nas revistas ilustradas (1897-1945).

Ao ser avaliada como problema étnico e político, a imigração ganhou espaço nas sessões políticas e científicas - e posteriormente nos arquivos históricos -, rotulada como "questão": questão chinesa, questão japonesa, questão judaica, etc. Tanto o imigrante japonês como os judeus eram bem-vindos desde que se integrassem ao "nós", atendendo às regras impostas pelos ordenadores da sociedade brasileira. Se no primeiro momento foram interpretados como inoportunos por sua "raça, durante a Segunda Guerra Mundial foram questionados por suas identidades étnicas" e interesses imperialistas. Porém, nem todos os países tornavam públicas suas ideias e seus atos de exclusão, preocupados que estavam em construir uma imagem de nação calcada, muitas vezes, em ideais humanísticos e democráticos (ainda que falsos). É quando a elite ordenadora saiu em busca de fundamentos políticos, raciais e até mesmo religiosos, para justificar os atos legais (e ilegais) de exclusão. Ao negar os valores do "outro" - avaliado como um estranho à realidade nacional - o grupo dominante "garante" valores positivos para os seus membros. Daí a segregação estar a um passo da exclusão.

Devemos considerar que os momentos de crise aguda - quando os valores têm de ser reordenados - possibilitam o (re)aparecimento de ações intolerantes que, diante do recuo das instituições liberais, oferecem soluções políticas baseadas na repressão e no terror. Por exemplo, o clima de instabilidade econômica, 
desemprego, miséria e fome que caracterizou o período de entre-guerras favoreceu uma verdadeira inversão de valores possibilitando soluções autoritárias fundadas na ideia de salvação. Múltiplos eram os discursos que, em nome da fé católica ou do Estado, se propunham a salvar a pátria do elemento intruso e proteger a nação da contaminação das raças inferiores ou das ideias exóticas.

Mesmo antes da Abolição da escravatura, instalou-se no Brasil imperial um amplo debate sobre a conveniência de se receber trabalhadores de origem asiática em substituição ao negro. Podemos datar como sendo da época de D. João VI as primeiras leis relativas à imigração e colonização no Brasil. Tal iniciativa incentivou a formação de núcleos pioneiros de colonos alemães, açorianos e suíços distribuídos pelo Espírito Santo, Rio de Janeiro e Santa Catarina. A opção pelos chins como mão de obra substitutiva do negro escravo foi retomada entre 1854-1855 através do sistema de parceria. Em junho de 1855, cerca de 2 mil chins eram esperados como prática de um contrato entre o governo brasileiro e a Casa Sampson e Tappman, de Boston. Chegaram apenas 368. Da euforia passou-se rapidamente ao desgosto. O tratamento negativo dado aos "novos escravos" culminou no rompimento do contrato e na formulação de um discurso estereotipado contra os chineses, rotulados como "inúteis", "indolentes", "indisciplinados".

Em 9 de julho de 1870, foi aprovado o decreto $\mathrm{n}^{o} 4.547$, que legislava sobre a introdução de asiáticos no Brasil com a anuência de Diogo Velho Cavalcanti de Albuquerque, ministro e secretário de Estado de Negócios da Agricultura, Comércio e Obras Públicas. Com o objetivo de efetivar esse ato legisla- tivo, foi criada a Sociedade Importadora de Trabalhadores Asiáticos, dirigida por Manoel José da Costa Lima e João Antônio de Miranda e Silva. A ideia inicial era a de que os chins permanecessem no Brasil por dez anos, não fosse a intervenção das autoridades inglesas e portuguesas que proibiram a saída dos coolies via Hong Kong e Macau. Em 1874, cerca de mil chineses conseguiram embarcar via Cantão com destino aos portos brasileiros.

Impressões preconceituosas eram sustentadas por membros da elite intelectual, dentre os quais cabe citar o conselheiro Manoel Felizardo de Souza e Mello, diretor da Repartição Geral das Terras Públicas, Oliveira Martins e o fazendeiro Luis Peixoto Lacerda de Werneck, advogado formado na Academia de Paris e na Universidade de Roma. Para este último, a raça chinesa "estacionária de uma civilização duvidosa inerte no progresso há de ceder lugar, de ser extenuada e destruída pelas nações provectas da Europa e da América [...]". Se para Oliveira Martins a ideia de um "Brasil chinês" era repugnante, para Souza e Mello, deveríamos nos dar "por felizes por livrar-nos dessa importação de semelhante gente que decerto ninguém receberá" (Dezem, 2005, p. 26).

Uma avaliação preconcebida trouxe para o debate as teorias pró-imigrantes brancos e europeus - interpretados como racialmente superiores em oposição aos chineses -, os africanos e os mestiços brasileiros, avaliados como "descendentes de raças não viris e pouco inclinados ao trabalho". Mesmo assim, alguns racialistas não descartavam totalmente a adoção de trabalhadores da raça amarela, classificada como intermediária, como uma solução provisória, em regime de trabalho de semiescravidão. Compactuava 
desta opinião Irineu Evangelista de Souza, o Visconde de Mauá ${ }^{4}$.

A consolidação da imagem do Brasil como nação branca e civilizada dominou os discursos proferidos durante o Congresso Agrícola de 1878. Uma série de impressos cuidaram de documentar os diferentes apartes pró e contra os chineses e favoráveis à adoção de uma política imigratória seletiva. Foi sob esse viés que se instalou um debate de cunho racial, econômico e político que ficou conhecido como "a questão chinesa" (1879). Discursos panfletários colocaram em cena as qualidades positivas do branco europeu em oposição aos perfis negativos dos chins e dos negros. Para os abolicionistas, o chinês era pior que o negro: "avaro, viciado em jogo e ópio, infanticida por convicção e ladrão por instinto". (Azevedo, 1987, pp. 90 e 147; Bosi, 1992).

No calor das mudanças efetivadas entre 1888 e 1889, em meio à Abolição da escravatura e à Proclamação da República, a política imigratória ganhou forma, revelando o ideal de branqueamento como parte do projeto étnico-político defendido pelo recém-empossado Governo Provisório. Sob o signo da nova ordem republicana, foi promulgado o Decreto n. 528, de 28 de junho de 1890, regulamentando a introdução de imigrantes

4 Foi a partir de 1879 que um discurso racista emergiu em meio ao debate político sustentado por imigrantistas e abolicionistas. Muitos tinham como referência a entrada no Rio de Janeiro, em 1814, de cerca de 200 a 500 coolies ou culis chineses trazidos de Macau por D. João VI para trabalhar no cultivo de chá em áreas experimentais. $\mathrm{O}$ fracasso dessa experiência dispersou parte desses colonos para Minas Gerais e São Paulo; outros permaneceram no Rio de Janeiro, ocupando a região entre o Morro do Castelo e o mar e ao longo da Rua da Misericórdia. Em 1877, a Sociedade Importadora publicou a obra As conveniências e vantagens à lavoura brasileira pela introdução de trabalhadores asiáticos - da China (apud Dezem, 2005, pp. 26-30). no Brasil, desde que aptos para o trabalho. "Indígenas da Ásia ou da África somente mediante autorização do Congresso Nacional [...]". Essa exceção foi corrigida pela Lei n. 97, de 5 de outubro de 1892, que permitia a livre entrada de imigrantes chineses e japoneses em território nacional, desde que não fossem "indigentes, mendigos, piratas, nem sujeitos à ação criminal em seus países”. Cobrava-se, mais uma vez, a aptidão para os trabalhos em qualquer indústria (Dezem, 2005, pp. 70-2; Demoro, 1960, p. 59).

Tendo em vista o modelo ideal de "bom trabalhador", o governo de Floriano Peixoto enviou uma missão diplomática ao Oriente Médio com o objetivo de incentivar a vinda de imigrantes para o Brasil. O encarregado José da Costa Azevedo, Barão de Ladário, optou pelos japoneses ("mais trabalhadores e econômicos"), pois os chineses, na sua opinião, eram "um mal moral para o Brasil". Tal veredito direcionou os olhares para o Japão. O debate no Senado e na Câmara dos Deputados - cujos anais registraram as diferentes opiniões acerca de uma política imigratória restritiva - culminou com a assinatura do Tratado de Amizade, Comércio e Navegação em 5 de novembro de 1895, sancionado pela Presidência da República em 27 de novembro de 1896 (Abranches, 1918, p. 494 apud Dezem, 2005, p. 72; Anais, 1896). No entanto, as barreiras do preconceito contra os asiáticos se faziam pulsar em cada estado de maneira diferenciada: o estado de São Paulo, ao contrário de Minas Gerais, que admitia asiáticos, permitia apenas a entrada de imigrantes brancos, privilegiando os europeus, americanos e os canarinos/africanos (Lei Estadual n. 365, de 1895, p. 6).

A partir de 1886, após a criação da Sociedade Promotora da Imigração pelo governo de 
São Paulo, intensificou-se o fluxo imigratório de italianos e portugueses para as fazendas de café. Estes, sobrevivendo em regime de semiescravidão, entraram em conflito com os proprietários de terras, interessados apenas no contrato de mão de obra barata. Caía por terra a imagem idílica do Brasil - de país-hospedeiro a todas as etnias - e que nem sempre correspondeu à realidade vivenciada pelos imigrantes radicados nas fazendas de café ou nos grandes centros urbanos. Tanto assim que, em 1902, uma série de denúncias levou o governo italiano, segundo Love, a encerrar as atividades de agências dedicadas ao recrutamento de imigrantes na Itália (Love, 1982, p. 28; Mialhe, 2003, pp. 209-32).

As estatísticas demonstram que os preferidos em todo o Brasil eram os brancos europeus. No período de 1890-1899 entraram no país 690.365 italianos, 219.653 portugueses, 164.293 espanhóis e 17.084 alemães ${ }^{5}$. Estes números, somados aos totais alcançados por cada nacionalidade ao longo das três primeiras décadas do século XX, serão recuperados a partir de 1934 para quantificar as cotas disponibilizadas aos interessados em obter vistos de entrada para o Brasil. É óbvio que a média obtida favorecia o ingresso de brancos em detrimento de imigrantes das raças negra e amarela. Basta observar os parágrafos 6 e 7 do Artigo 121 da Constituição de 1934, que impunham restrições à entrada de imigrantes no território nacional de forma a garantir a integração étnica. A corrente imigratória de cada país não deveria exceder anualmente o limite de

5 "Discriminação por nacionalidade dos imigrantes entrados no Brasil no período de 1884-1939", in Revista de Imigração e Colonização, vol. 1, n. 3, pp. 617-642, jul. 1940.
$2 \%$ sobre o número total dos respectivos nacionais fixados no Brasil durante os últimos 50 anos (Carneiro, 2001, pp. 62-4).

Nacionalismo exacerbado e xenofobia serviram de elementos catalisadores para o debate mascarado pela intenção de "garantir a integração étnica e a capacidade física e cívica do imigrante" $"$.

\section{IMAGENS DA MODERNIDADE}

No final do século XIX e início do XX, pairava no ar o projeto de modernidade idealizado pela burguesia cafeeira, cuja hegemonia se fazia garantida pelos governadores manejados pelo governo federal e o patrimonialismo em assuntos privados e públicos (cafeicultores do Oeste paulista em aliança com canavieiros, pecuaristas, seringalistas, etc.). No entanto, a circulação de múltiplos discursos acerca da adoção deste ou daquele imigrante para trabalhar na lavoura nos coloca diante do conflito de diferentes projetos. Falava-se em modernidade mas as estruturas jurídicas eram medíocres e carregadas de anacronismos, herança dos tempos coloniais. A sociedade apresentava-se esgarçada pela persistência do escravismo e por valores racistas seculares. Enfim, com a República colocava-se em prática uma política de aparências que alimentava "um mundo de ilusões".

6 Entre 1908 e 1923 entraram no Brasil 32 mil japoneses, muitos dos quais incentivados pelo contrato firmado entre o governo paulista e a Companhia Imperial de Imigração, sediada em Tóquio. Iniciativa isolada que, apesar de não ter longevidade, prestou-se para tornar "visível" o perigo amarelo e para quantificar a pequena cota reservada aos asiáticos a partir de 1934. Em 18 de junho de 1908 aportou em Santos um grupo de 8.781 imigrantes japoneses contratados para trabalhar na lavoura cafeeira, além de 12 avulsos. 
Nesse cenário, as revistas ilustradas cumpriram com o seu papel de formar a opinião pública. Fotografias, charges políticas e "conhecimentos úteis" transformaram esse gênero de impresso em importante fonte para os estudos da questão imigratória. Lembraria aqui a Revue du Brésil, que, entre 1896 e 1897, procurava "tirar dúvidas" sobre a imigração; e a Revista Moderna, dedicada a veicular uma imagem otimista do país, associada à qualificação da lavoura e dos meios de transportes, símbolos expressivos do progresso. Dentre as raridades está a revista O Immigrante, bissemanário com publicação às segundas e quintas-feiras, que propunha advogar os interessses dos imigrantes, sendo redigido e de propriedade de R. Gismond (Martins, 2001). Álbuns fotográficos comemorativos, editados a partir de 1887, difundiram a imagem idílica do país tropical alimentando, no âmbito do imaginário coletivo, a ideia de um Brasil moderno, aberto aos trabalhadores imigrantes. As revistas ilustradas e os cartões-postais também colaboravam para oficializar a imagem de harmonia e progresso urbano, componentes adequados para a composição do discurso oficial. Estratégias como essas atendiam aos interesses das elites agrária e industrial que procuravam adaptar-se às novas circunstâncias do mercado internacional ${ }^{7}$.

7 Publicações italianas, principalmente, procuravam divulgar atrativos cenários industriais e rurais onde a figura do imigrante aparecia com componentes positivos. Como exemplos destas formas de representação da cidade e do operário estrangeiro citamos as publicações italianas Gli Italiani nel Brasile (1922), II Brasile e gli italiani (1906); o álbum Casa di Salute E. Matarazzo (s./d.); o Livro de Ouro do Estado de São Paulo (1914) e a edição comemorativa A Capital Paulista Comemorando o Centenário da Independência, 1922 (1922). Cf. Lima \& Carvalho (1997, p. 147).

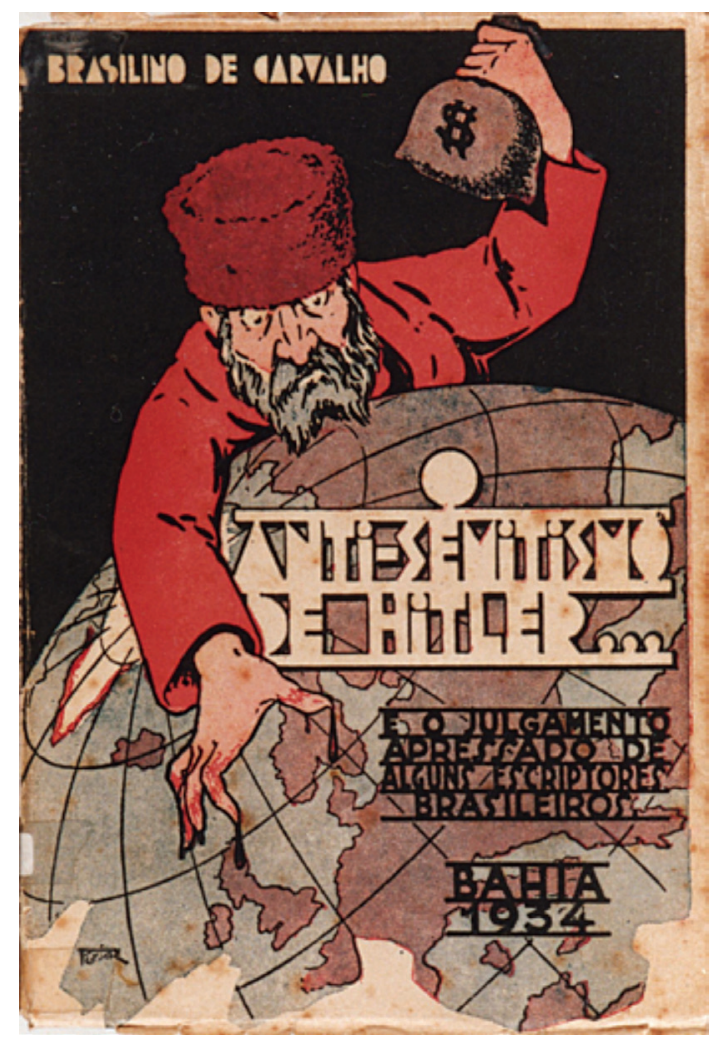

O perigo judaico-comunista representado na obra de Brasilino de Carvalho. O antissemitismo de Hitler. Bahia, 1934. Acervo Tucci/SP

Podemos considerar que o projeto étnico-político defendido pelo governo Vargas caracterizado pelo ideal de higienização da raça inspirado no racismo e na xenofobia dos regimes nazifascistas - manteve o conceito de homogeneidade racial sustentado pelos teóricos eugenistas do final do século. As ideias que inspiraram as emendas para a nova Constituição de 1934 nada mais fizeram do que preservar a tradicional política de aparências, ao aprovar o sistema de cotas para a imigração. Três anos depois, a aprovação da primeira circular secreta contra a entrada de imigrantes "semitas" no Brasil levaria ao auge o antissemitismo político implantado pelo governo Vargas. Persistiam os mitos da democracia racial, 
do homem cordial brasileiro e da conspiração judaico-comunista.

Mitos políticos foram acionados com o objetivo de justificar os atos de repressão contra as minorias étnicas avaliadas como perigosas à configuração de uma raça pura e à ordenação social da sociedade. Tradicionais "etiquetas" racistas se prestaram para legitimar a continuidade de alguns poucos no poder. Importadas da Europa no final do século XIX, essas teorias sustentaram, por mais de meio século, um caloroso debate sobre qual seria a melhor raça para compor o povo brasileiro: a amarela, branca ou a negra? Que tipo étnico deveria ser incentivado a emigrar para o Brasil?

Uma intensa campanha de brasilidade ufanista, antiliberal, anticomunista e xenófoba - aprimorada nos anos de 1930 e 1940 do século XX - prestou-se para encobrir valores racistas e antissemitas endossados pela elite política brasileira. Por meio do slogan "promover o homem brasileiro e defender o desenvolvimento econômico e a paz social do país", o Estado republicano encontrou uma fórmula eficaz para acobertar uma série de práticas autoritárias aprimoradas durante o governo Vargas. Expressiva da campanha antinipônica é a capa do livro A ofensiva japonesa no Brasil, de Carlos de Souza Moraes (1942), onde os japoneses aparecem representados com semblantes cadavéricos, expressões de terror, sorrisos falsos, semblantes sedutores (gueixa) ou com postura de um dorminhoco, preguiçoso.

Através de imagens como essa, identificamos o discurso de um Estado que se queria forte e que não poderia admitir fissuras, daí o combate a certos grupos estrangeiros avaliados como elementos de erosão. Acontecimentos políticos internacionais, como a Guer-

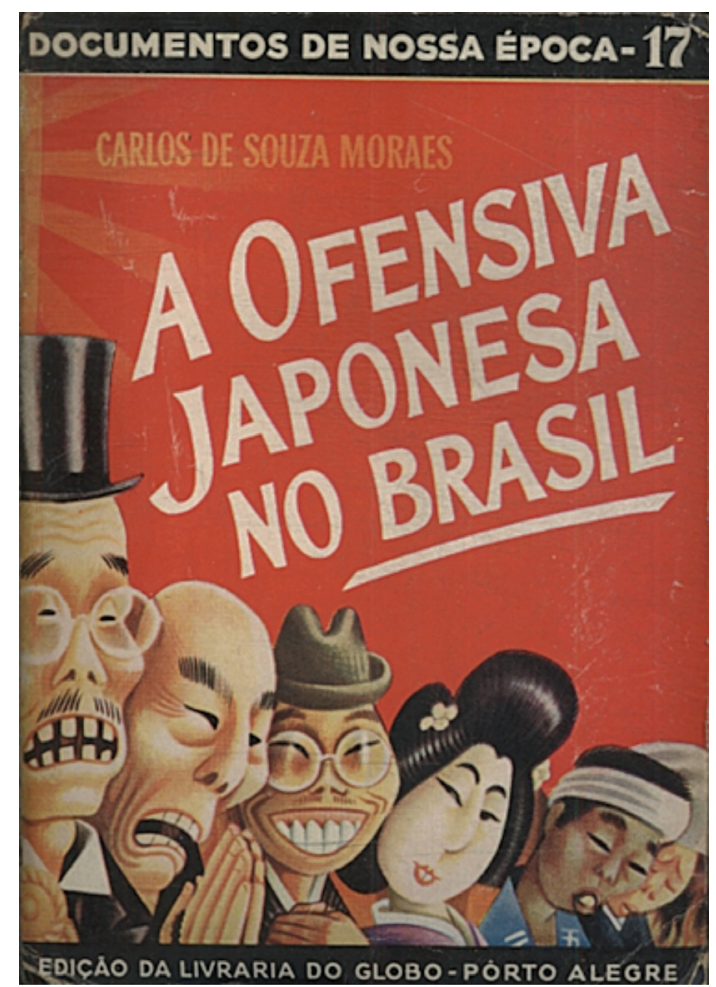

Imagens estereotipadas dos japoneses no livro A ofensiva japonesa no Brasil, 1942. Acervo Tucci/SP

ra Russo-Japonesa (1904-1905), a Revolução Bolchevique (1917) e o desmoronamento do Império Otomano, colaboravam para firmar junto às autoridades da imigração brasileira a imagem negativa de certos grupos de imigrantes, dentre os quais aqueles vindos do Oriente. Pregava-se a homogeneidade em substituição à diversidade remando-se contra a maré das políticas democráticas que davam ênfase à cidadania e aos direitos iguais para todos os cidadãos, fossem estes nacionais ou estrangeiros. Estava em questão a concepção orgânica de sociedade cuja imagem se fazia, na maioria das vezes, modelada pelo discurso do grupo dominante.

Por mais de meio século, intelectuais e políticos brasileiros defenderam a ideia de que os imigrantes deveriam "despir-se de 


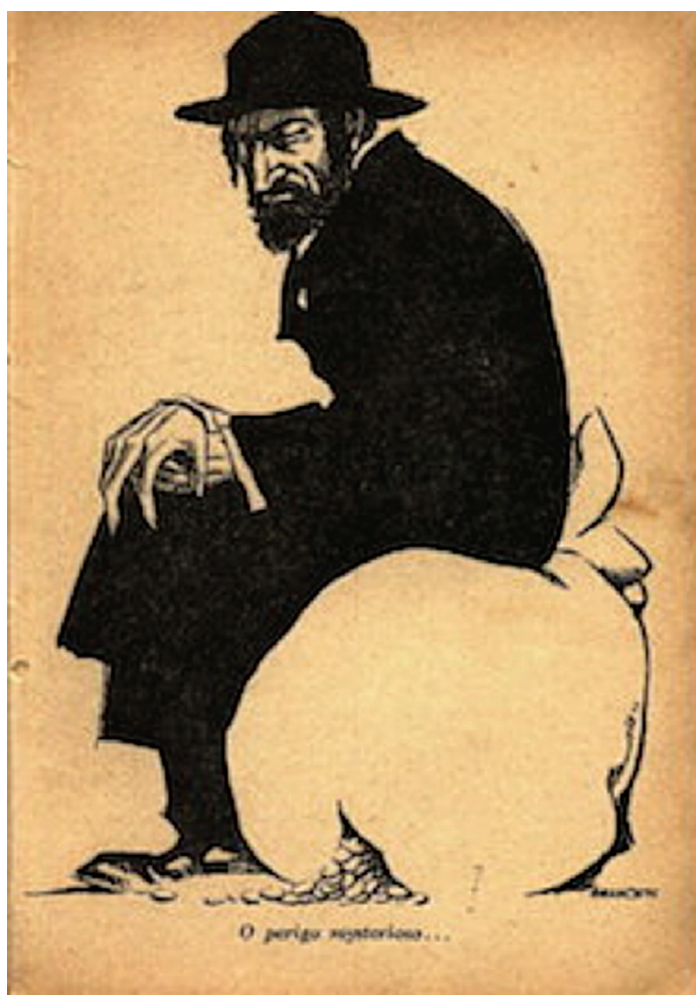

Belmonte, O perigo misterioso. Desenho reproduzido da sua obra Ideias de ninguém. Rio de Janeiro, José Olympio Editora, 1935. Acervo Tucci/SP

seus vínculos de origem para renascerem com identidades renovadas". Esse processo de assimilação/integração nacional acabou por favorecer a miscigenação racial que, nos anos de 1930, prestou-se como elemento para a construção do mito da democracia racial no Brasil. No entanto, os registros deixados por aqueles que se dedicavam a "regulamentar" a imigração no Brasil e a controlar a massa de estrangeiros radicados em território nacional, demonstram que nem sempre os imigrantes atendiam ao modelo de cidadão idealizado pelo Estado nacional. Desumanizava-se os "indesejáveis", cuja imagem era demonizada ou animalizada enquanto símbolo da desordem e/ou da inferioridade racial, como aconteceu com a imagem do judeu. Por meio de analogias com vermes, serpentes, polvos, tubarões e hidras monumentais, eles eram responsabilizados pela fome, pelo desemprego, pela prostituição e pelo atraso econômico.

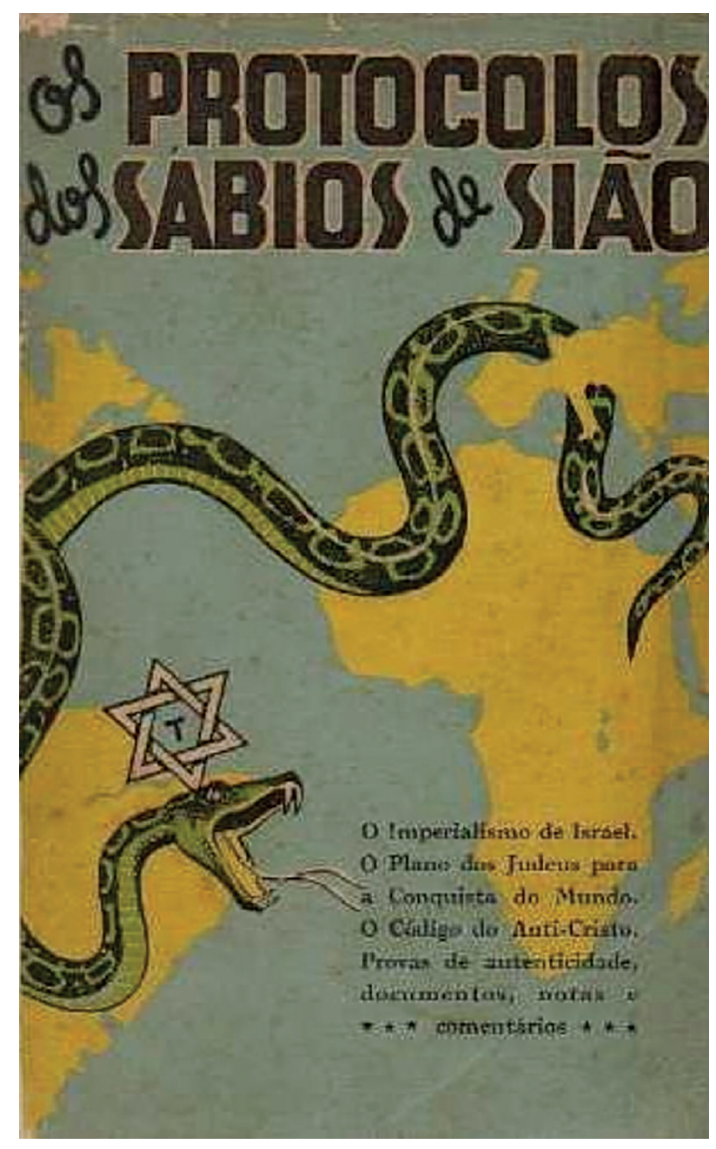

A animalizacão do judeu. Os protocolos dos sábios de Sião. Tradução de Gustavo Barroso. São Paulo, 1936. Acervo Tucci/SP 


\section{BIBLIOGRAFIA}

AZEVEDO, Celia Marinho. Onda negra, medo branco: o negro no imaginário das elites, século XIX. São Paulo, Paz e Terra, 1987.

BOSI, Alfredo. A dialética da colonização. São Paulo, Companhia das Letras, 1992. BECKER, Howard S. Outsiders: estudos de sociologia do desvio. São Paulo, Zahar, 2008.

BOARINI, Maria Lúcia (org.). Higiene e raça como projetos: higienismo e eugenismo no Brasil. Maringá, Eduem, 2003.

BRISSOLI FILHO, Francisco. Estigmas da criminalização: dos antecedentes à reincidência criminal. Florianópolis, Obra Jurídica, 1998.

CARNEIRO, Maria Luiza Tucci; TAKEUCHI, Márcia Yumi (orgs.). Imigrantes japoneses no Brasil. Trajetória, imaginário e memória. São Paulo, Edusp, 2010. O antissemitismo na Era Vargas. 3a ed. São Paulo, Perspectiva, 2001. "A biotipia do imigrante ideal: nem negro, nem semita, nem japonês", in Maria Luiza Tucci Carneiro; Márcia Yumi Takeuchi (orgs.). Imigrantes japoneses no Brasil. Trajetória, imaginário e memória. São Paulo, Edusp, 2010, pp. 64-96.

$\mathrm{CROCl}$, Federico. "A invasão nipônica: a imagem do imigrante japonês na comunidade italiana - solidariedade, rejeição e conflito", in Maria Luiza Tucci Carneiro; Márcia Yumi Takeuchi (orgs.). Imigrantes japoneses no Brasil. Trajetória, imaginário e memória. São Paulo, Edusp, 2010, pp. 275-336.

DEZEM, Rogério. Matizes do "amarelo". A gênese dos discursos sobre os orientais no Brasil, 1878-1908. São Paulo, Associação Editorial Humanitas/Lei/Fapesp, 2005.

FRANCASTEL, Pierre. Realidade Figurativa. São Paulo, Perspectiva, 1972.

GARLAND, David. A cultura do controle: crime e ordem social na sociedade contemporânea. Tradução de André Nascimento. Rio de Janeiro, Revan, 2008.

GOFFMAN, Ervin. Estigma: notas sobre a manipulação da identidade deteriorada. $4^{a} \mathrm{ed}$. Rio de Janeiro, Jorge Zahar, 1982.

KOIFMAN, Fábio. Imigrante ideal. O Ministério da Justiça e a entrada de estrangeiros no Brasil, 1941-1945. Rio de Janeiro, Civilização Brasileira, 2012.

KOSSOY, Boris. Efímero y lo perpetuo en la imagen fotográfica. Tradução de Luis Paresi. Madrid, Cátedra, 2014.

"Retratos e autorretratos: imigrantes japoneses no estado de São Paulo", in Maria Luiza Tucci Carneiro; Márcia Yumi Takeuchi (orgs.). Imigrantes japoneses no Brasil. Trajetória, imaginário e memória. São Paulo, Edusp, 2010, pp. 369-406.

KOSSOY, Boris; CARNEIRO, Maria Luiza Tucci. O olhar europeu: o negro na iconografia brasileira do século XIX. São Paulo, Edusp, 1994.

LESSER, Jeffrey. O Brasil e a questão judaica: imigração, diplomacia e preconceito. Rio de Janeiro, Imago, 1995.

LOVE, J. A locomotiva. São Paulo na Federação Brasileira (1889-1937). Tradução de Vera Alice Cardoso da Silva. Rio de Janeiro, Paz e Terra, 1982.

HOLLOWAY, Thomas H. Polícia no Rio de Janeiro: repressão e resistência numa cidade do século XIX. Tradução Francisco de Castro Azevedo. Rio de Janeiro, EFGV, 1997. 
LIMA, Solange Ferraz de; CARVALHO, Vânia Carneiro de. Fotografia e cidade. Da razão urbana à lógica de consumo. Álbuns de São Paulo (1887-1954). São Paulo, Mercado das Letras/Fapesp, 1997.

MARTINS, Ana Luiza. Revistas em revista. Imprensa e práticas culturais em tempos de República. São Paulo (1890-1922). São Paulo, Imprensa Oficial/Edusp/Fapesp, 2001. MENDONÇA, Sônia Regina de. Estado e historiografia no Brasil. Niterói, Eduff, 2006.

MEIHY, José Carlos Sebe Bom. A colônia brasilianista: história oral de vida acadêmica. São Paulo, Nova Stella, 1990.

MIALHE, Jorge Luiz. "Imigração e dupla nacionalidade: aspectos jurídicos", in Carlos Boucault; Teresa Malatian (orgs.). Políticas migratórias. Fronteiras dos direitos humanos no século XXI. Rio de Janeiro, Renovar, 2003, pp. 209-32.

MOVSCHOWITZ, Jeronymo. Nem negros, nem judeus: a política imigratória de Vargas e Dutra (1930-1954). Rio de Janeiro, PPGH/Uerj, 2001.

ROLLAND, Denis; SANTOS, Marie-José Ferreira dos Santos; RODRIGUES, Simile (coords.). Le Brésil, territoire d'histoire. historiographie du Brésil contemporain. Paris, L'Harmattan, 2013.

SALIBA, Elias Thomé. Raízes do riso. A representação humorística na história brasileira: da Belle Époque aos primeiros tempos do rádio. São Paulo, Companhia das Letras, 2002.

SILVA, Aldina C. F. da. "Vozes silenciadas: a imagem do imigrante japonês entre discursos, palavras e silêncios", in X Encontro Nacional de História Oral - Testemunhos: História e Política. UFPE, Recife, 26 a 30/4/2010.

TAKEUCHI, Márcia Yumi. Imigração japonesa nas revistas ilustradas. São Paulo, Edusp/ Fapesp, 2016. 